
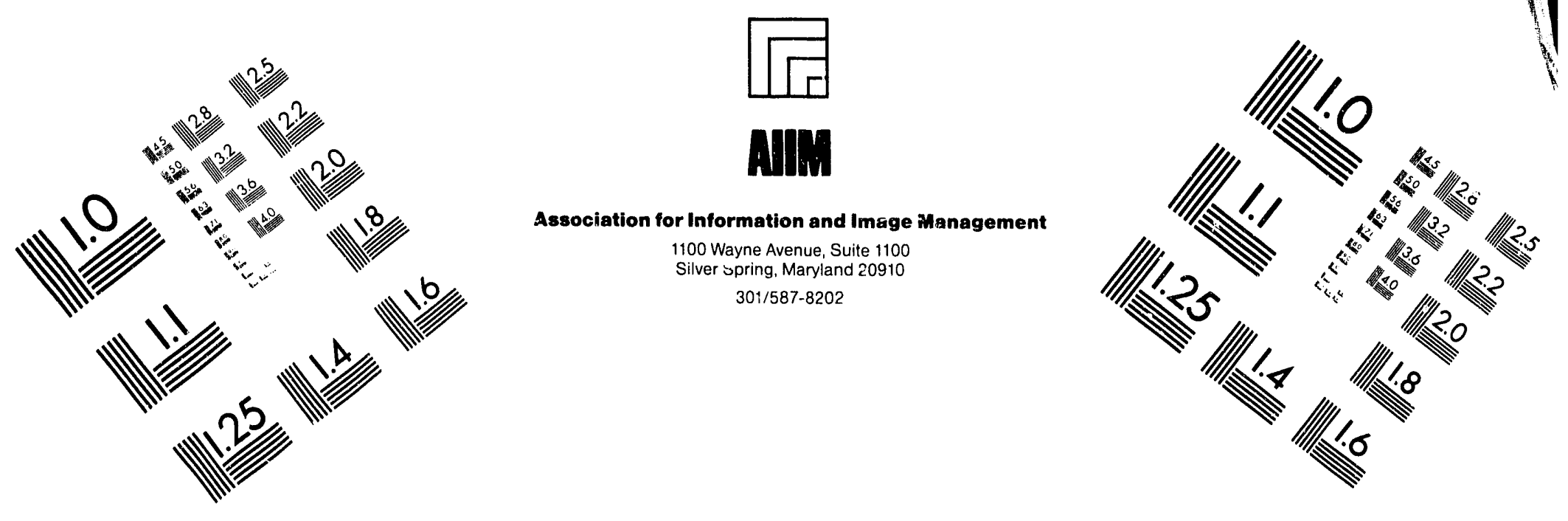

Centimeter

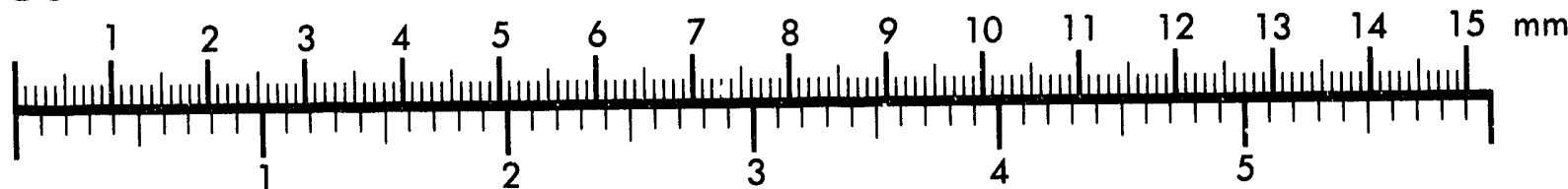

Inches
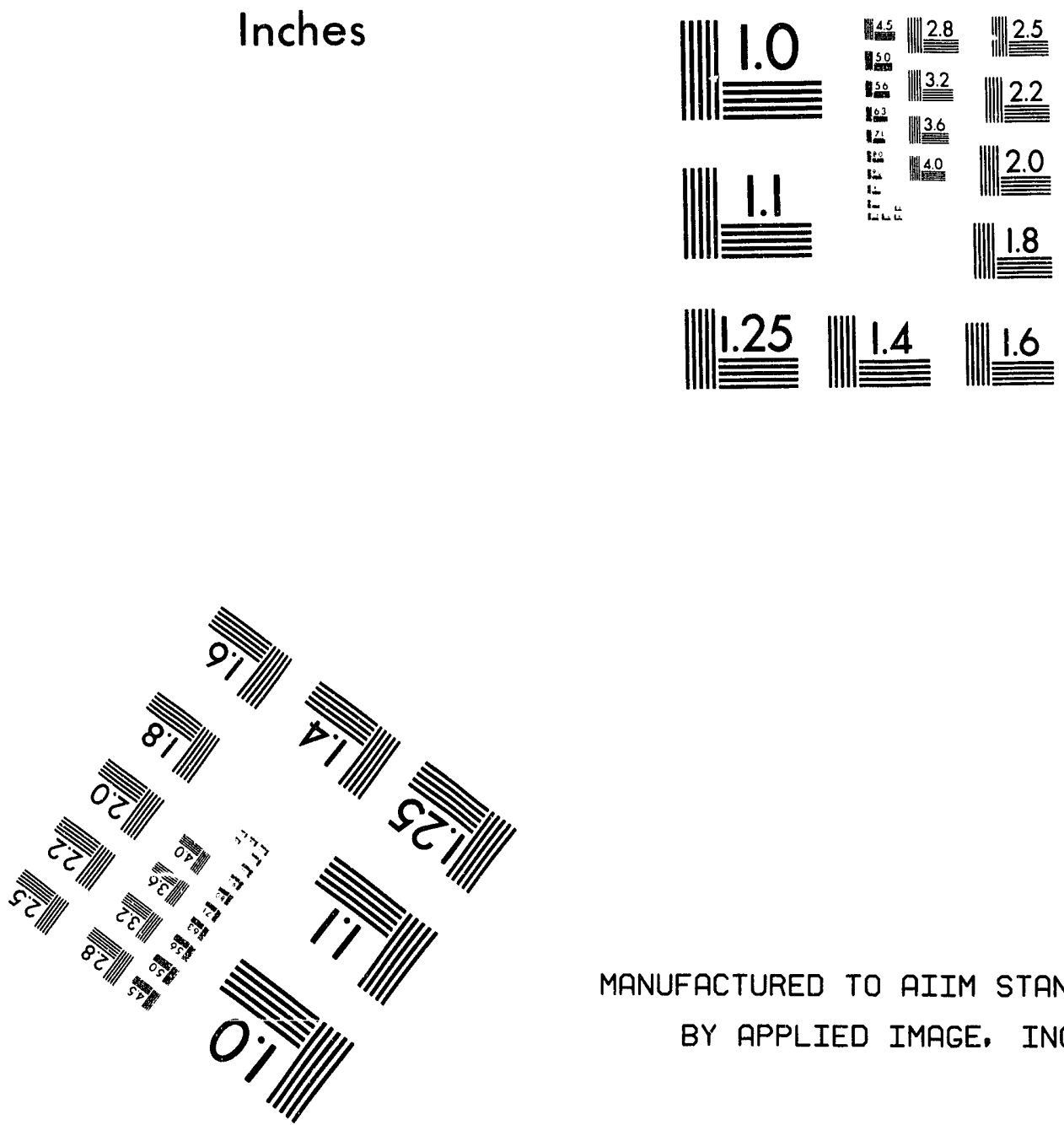

MANUFACTURED TO AIIM STANDARDS

BY APPLIED IMAGE. INC.

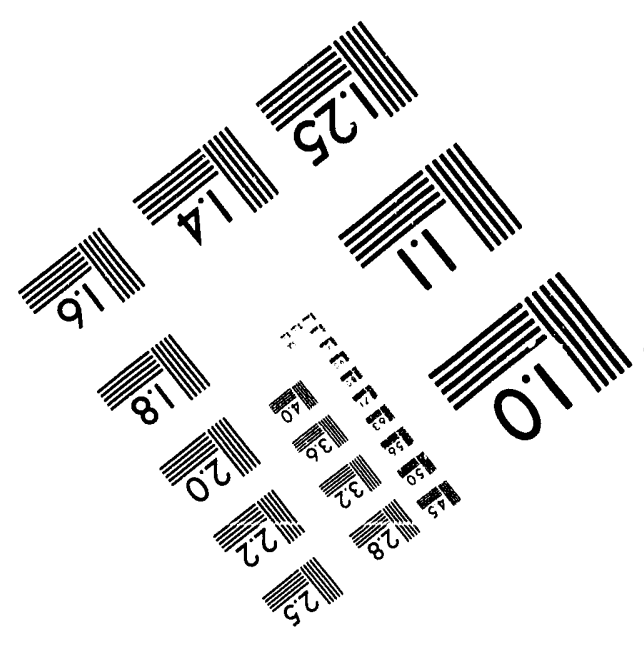



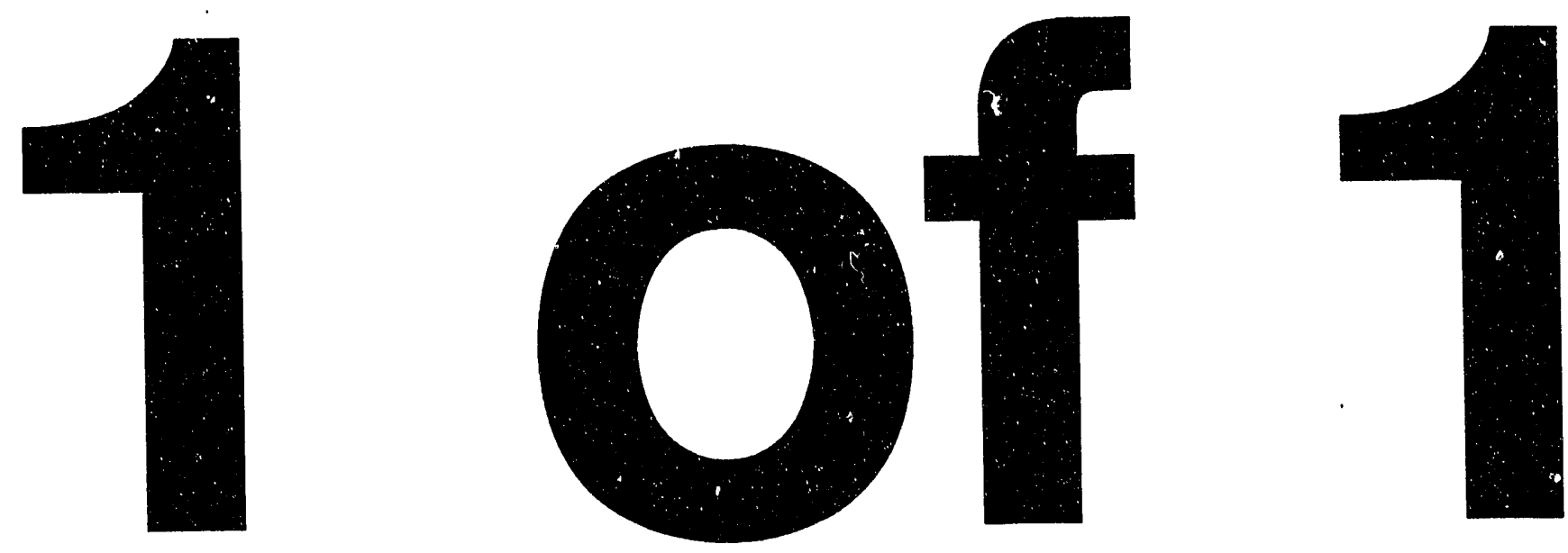
PYFITE THERMOCHEMISTRY, ASH AGGLOMERATION, AND CHAR FRAGMENTATION DURING PULVERIZED COAL COMBUSTION

Quarterly Report for the Period

March 15, 1988 - June 15, 1988

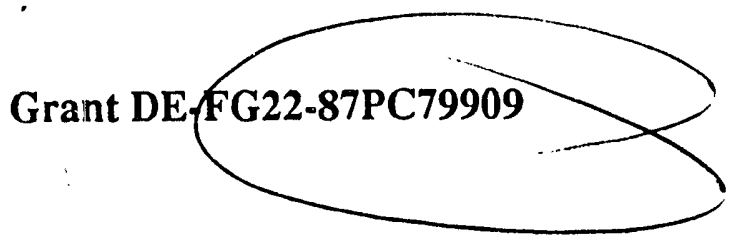

Prepared for

THE UNITED STATES DEPARTMENT OF ENERGY

Sayeed Akhtar

DOE Project Officer

Pittsburgh Energy Technology Center

Pittsburgh, PA 15236

Submitted by

Mr. Aniefiok Akan-Etuk, Assistant Professor Stephen Niksa and Professor Charles H. Kruger

August 1988

\section{HIGH TEMPERATURE GASDYNAMICS LABORATORY Mechanical Engineering Department \\ Stanford University \\ Pats

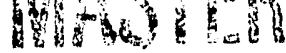

DISTRIBUTION OF THIS DOCUMENT IS UNLIMITED 


\title{
PYRITE THERMOCHEMISTRY, ASH AGGLOMERATION, AND CHAR FRAGMENTATION DURING PULVERIZED COAL COMBUSTION
}

\author{
Quarterly Report for the Period \\ March 15, 1988 - June 15, 1988 \\ Grant DE-FG22-87PC79909 \\ Prepared for \\ THE UNITED STATES DEPARTMENT OF ENERGY \\ Sayeed Akhtar \\ DOE Project Officer \\ Pittsburgh Energy Technology Center \\ Pittsburgh, PA 15236 \\ Submitted by \\ Mr. Aniefiok Akan-Etuk, Assistant Professor Stephen Niksa \\ and Professor Charles H. Kruger
}

This report was prepared as an account of work sponsored by the United States Government. Neither the United States nor the United States Department of Energy, nor any of their employees, makes any warranty, express or implied, or assumes any legal liability or responsibility for the accuracy, completeness, or usefulness of any information, apparatus, product or Frocess disclosed, or represents that its use would not infringe privately owned rights. Reference herein to any specific commercial product, process, or service by trade name, mark, manufacturer, or otherwise, does not necessarily constitute or imply its endorsement, recommendation, or favoring by the United States Government or any agency thereof. The views and opinions of authors expressed herein do not necessarily state or reflect those of the United States Government or any agency thereof.

August 1988

High Temperature Gasdynamics Laboratory

Department of Mechanical Engineering

Stanford University 


\section{TABLE OF CONTENTS}

Page

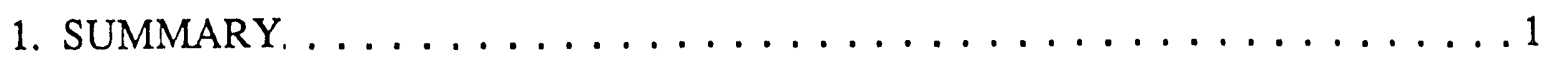

2. INTRODUCTION TO THE PROGRAM $\ldots \ldots \ldots \ldots \ldots \ldots \ldots \ldots$

3. SCOPE OF THE REPORTED ACTIVITY $\ldots \ldots \ldots \ldots \ldots \ldots \ldots$

4. FINDINGS $\ldots \ldots \ldots \ldots \ldots \ldots \ldots \ldots \ldots \ldots \ldots \ldots \ldots \ldots \ldots \ldots \ldots \ldots$

4.1 Introduction $\ldots \ldots \ldots \ldots \ldots \ldots \ldots \ldots \ldots \ldots \ldots \ldots \ldots \ldots \ldots \ldots$

4.2 Characterization of the Sampling Probe $\ldots \ldots \ldots \ldots \ldots \ldots$

4.3 Probe Housing and Exhaust $\ldots \ldots \ldots \ldots \ldots \ldots \ldots \ldots$

4.4 Carbon Synthesis $\ldots \ldots \ldots \ldots \ldots \ldots \ldots \ldots$

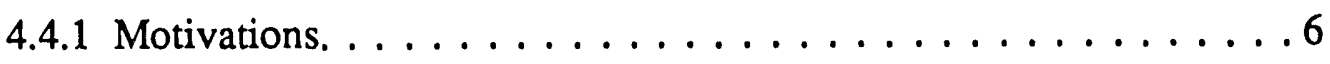

4.4.2 The Synthesis Procedure . . . . . . . . . . . . 6

5. SHORT RANGE OBJECTIVES $\ldots \ldots \ldots \ldots \ldots \ldots \ldots$

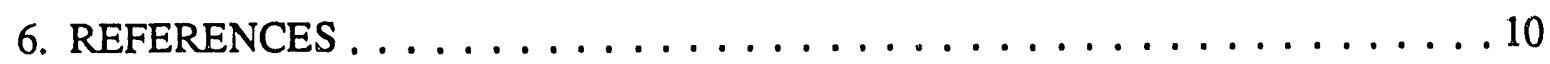

\section{APPENDIX A}

DESIGN DRAWINGS FOR THE RAPID-QUENCHING SAMPLING PROBE APPENDIX B

DETAILED PROCEDURES FOR SYNTHETIC CHAR POLYMERIZATION 


\section{SUMMARY}

During the period March 15, 1988 through June 15, 1988 we continued to develop the components for representative sampling of particulates in our one-dimensional coal flow reactor, and also began to synthesize carbons with controlled porosity and pyrite loadings. The first element in the collection and analysis train, the extraction probe for solid samples, is complete. In shakedown evaluations, the probe met all design specifications and is ready for use. A housing for the probe was designed and is now being fabricated. This component supports the sampling probe at specified positions in ine Stanford Coal Flow Reactor (SCFR), and also collects and quenches the effluent from the reactor, and transports it to the labrratory exhaust system.

We have synthesized carbons from furfuryl alcohol, according to the procedure developed by Senior and Flagan at Caltech. These carbons are virtually identical to samples prepared at Caltech, and SEM-photomicrographs confirmed that the carbon is glassy with no large pores. We perturbed the synthesis procedure in various ways to attempt to control viscosity and foaming during the curing stage, but saw only marginal improvemenis. 


\section{INTRODUCTION TO THE PROGRAM}

During p.f. firing of coal, the evolution of particulate ash from extraneous mineral matter is determined by thermochemistry, agglomeration of molten inclusions as the char is consumed, and fragmentation of the char into finer particulates. Our three-year research program aims for a fundamental understanding of these chemical and physical dynamics, to motivate control strategies for fouling and slagging problems. The transformation of pyrite inclusions into iron oxide ash is the primary focus, including pyrite thermochemistry, the average number of ash particles per char particle, and the relation between the size distrioutions and composition of mineral inclusions and ash particles.

Iron-ash evolution can be properly characterized only when the initial composition and size distribution of the mineral inclusions are known. The proposed research therefore utilizes synthetic chars with monodisperse pyrite inclusions and a range of controlled pore structures, including the mesosphere structures common to $\mathrm{p}$. f. firing. Studies with the synthetic char establish an essential reference condition for analyzing the behavior of coal char. The size distributions and compositions of ash particulates form both the synthetic chars and coal chars will be monitored during simulated p.f. firing in the Stanford turbulent coal flow reactor.

The experiments are aimed at two advances. First, the pyrite thermochemistry studies will identify any kinetic constraints among the iron-bearing compounds during p.f. firing, as an important step toward predicting ash compositions from mineral matter compositions. Second, the fragmentation studies promote a fresh approach to modeling the size distribution of ash known as the percolate fragmentation model. While this model has distinct conceptual advantages over deterministic pore models, experiments of the sort proposed here are essential to realizing the model's full potential for utility boiler applications. And the model's general applicability will be stringently evaluated from the studies with actual coal char. 


\section{SCOPE OF THE REPORTED ACTIVITY}

Our proposed studies of pyrite thermochemistry and fragmentation rely heavily on representative sampling of the solid products throughout the a one-dimensional flow reactor. During this reporting period we received and tested the sampling probe, and designed a probe housing which quenches and vents the reactor exhaust. Furthermore, we succeeded in producing synthetic carbons of controlled porosity, as the first step on the way toward carbons with only large internal voids and specified pyrite loadings. 


\section{FINDINGS}

\subsection{Introduction}

The primary topics in this program are the size distribution of particulates from pulverized coal firing and the thermochemical transformations of pyrite at typical p. f. firing conditions. In the laboratory, both of these aspects involve representative sampling of particulates from a high temperature combustor, as well as synthetic model fuels with specified pore structure and pyrite loadings. We continued to develop the components and laboratory procedures for these studies, by confirming the performance of our sampling probe; designing a probe housing; and synthesizing glassy carbons which do not contain macropores.

\subsection{Characterization of the Sampling Probe}

The design of the sampling probe was discussed in the previous quarterly. Its layout is largely based on the probe which has been used at Sandia, which also uses helium as the coolant gas. The extracted gases are mixed with the coolant gas at the inlet, then transported in a central channel as the product stream. The product and coolant streams are insulated from the reactor using two channels of cooling water. Between the water and product channels there are two separate channels for the helium coolant. One delivers the coolant gas to the jets at the probe tip for thermal quenching; a second channel passes helium through sintered stainless steel tubing to establish a transpiring, radial flow into the product channel. The transpiring stream is added to minimize wall deposition, and has proven to be effective in recent sampling schemes used by Sarofim and coworkers at MIT.

After receiving the probe from the fabricator, we tested the integrity of each channel using argon at 10 and 50 psig. The test conditions are summarized in Table 1. All channels are leak-tight, and the flow paths were assembled properly. The sintered stainless tube passed a radial stream at the specified flow rates. 
Table I. Argon Flow Rates Through Probe's Internal Channels

\begin{tabular}{|llclc|}
\hline Entry Port & Exit Port & $\mathrm{P}(\mathrm{psia})^{\star}$ & Closed Ports & Flow $(\mathrm{L} / \mathrm{min})^{\star \star}$ \\
\hline \multirow{2}{*}{$\mathrm{H}_{2}$ inlet } & \multirow{2}{*}{$\mathrm{H}_{2}$ O outlet } & 10 & none & \\
& & & He inlets & 7.14 \\
& & & He inlets, probe front & 7.14 \\
& & 50 & all & 7.14 \\
& & & none & 12.14 \\
Quench He & Probe back & 9.5 & Transpired he, probe front & 4.35 \\
& & 9.5 & all & 4.35 \\
Transpired He & Probe back & 50 & none & 15.0 \\
& & & Quench He & 28.8 \\
& & & all & 28.7 \\
\hline
\end{tabular}

*P is the pressure of the argon tank's regulator.

**The flowmeter setting was $10 \mathrm{~cm}$ for testing the $\mathrm{H}_{2} \mathrm{O}$ channels and $14 \mathrm{~cm}$ for testing the He channels.

\subsection{Probe Housing and Exhaust}

The sampling probe will be stationed in the SCFR within a housing which also directs the hot effluent gases to the laboratory exhaust system. As seen in the design drawings in Appendix A, the main chamber in the housing is a 10 by 6.75 in stainless tube, equipped with four water spray nozzles which will quench the effluent. The effluent gases are transported to an exhaust duct through a sidearm, while the cooling water is drained through the housing floor.

The sampling probe penetrates the housing floor through an O-ring seal, and is supported further by a circular guide. The guide ring can be moved to finely adjust the transverse position of the probe in the reactor. The vertical position of the probe tip is adjustable over a wide range, and maintained with a set screw. The entire housing is connected to a flexible exhaust duct and mounted on a cart, for lateral traversing.

The housing has been submitted for fabrication, and should be received in the coming quarter. 


\subsection{Carbon Synthesis}

\subsubsection{Motivations}

During p.f. firing of coal, the evolution of particulate ash from extraneous mineral matter involves thermochemistry, agglomeration of molten inclusions as the char is consumed, and fragmentation of the char into finer particulates. Bearing in mind that each of the aspects is not yet understood in detail, iron-ash evolution can be properly characterized only when the initial composition and size distribution of the mineral inclusions are known, and when the pore size distribution is fully characterized. Since neither stipulation can be met for coal chars, we will initially focus on synthetic carbons with controlled pore structures and pyrite loadings.

Progress in synthesizing these materials is summarized in the following sections.

\subsubsection{The Synthesis Procedure}

Various schemes for carbon synthesis have been developed over the past few decades. We adopted that of Senior and Flagan at Caltech (1), which is a modification of Walker's synthesis process. Furfuryl alcohol is processed as the monomer in a catalyzed polymerization, using p-toluenosulfonic acid (PTSA). After decanting the aqueous phase, a viscous polymer is cured at progressively higher temperatures, to convert it into a glassy carbon. The detailed procedure is explained in Appendix B.

These carbons are especially suitable for our purposes in that they contain no macropores; in fact, Senior reported that no pores larger than 15 Angstroms are present. We will add inclusions to control the evolution of macroporosity, including those to form voids of several microns, to create the mesosphere structures so often seen in the chars from p.f. firing. Closely sized pyrite particles will also be added, at prescribed loadings.

In our first attempts at synthesis, we were surprised to observe very large bubbles in the carbon samples, which clearly indicated that the melts were foaming during one of the curing stages. Although portions of the carbons were smooth and glassy, like obsidian, larger regions contained centimeter sized voids. Naturally, given our aim for glassy carbons without macroporosity, we questioned our implementation of the procedure. But after contacting Flagan and coworkers at Caltech, we learned that the melts will indeed foam. The group at Caltech sent us one of their cured samples which appeared to be identical to ours. However, they also pointed out that the very large scale porosity is eliminated during grinding and classification into the p. f. size grade. 
The SEM micrographs in Fig. 1 confirm that this is the case. As seen in the high resolution (1440 power) image of a single particle, no large voids are present, and all surfaces are smooth and glassy. In Senior's samples, there were no pores larger than 15 Angstroms. In the near future, we will determine the pore size distributions of samples subjected to various pretreatment conditions.

Although the carbons prepared by Senior's procedure are suitable for the fragmentation studies once they have been ground, we also tried to modify the synthesis procedure to eliminate foaming. The remainder of this section summarizes these attempts, but only briefly because they were only marginally successful.

In the synthesis, water is the medium for introducing the PTSA catalyst and, even after decanting the aqueous phase, the viscous polymer contains substantial amounts of it. It is removed during four hours of dessication with water aspiration, followed by curing at $125 \mathrm{C}$ for 6 hours. Subsequent curing, at $200 \mathrm{C}$ for 10 hours and at $550 \mathrm{C}$ for one hour, expels unreacted monomers and small fragments, and noncondensible gases. Before dessication, the melts must be thinned with acetone so solids can be added. The acetone is driven off by the first curing stage. Even though we were not adding solids at this time, acetone was included to characterize its evaporation.

The melts begin to foam during the first curing stage, at roughly $100 \mathrm{C}$, and retain the vapor bubbles as the condensed phase solidifies after prolonged curing at $125 \mathrm{C}$. By modifying the synthesis procedure, to evaporate the water at $90 \mathrm{C}$ under reduced pressure, while the melt is still fluid, then raising the temperature to $125 \mathrm{C}$, we hoped to eliminate the foaming.

Aside from this modification, the other deviations from the Senior's procedure are thought to be inconsequential. The curing stages are conducted under argon instead of nitrogen. We use a hand-drill fit with a propeller for stirring at up to $1000 \mathrm{rpm}$, instead of $2000 \mathrm{rpm}$. Since the complete procedure is given in Appendix B, only the curing stages are discussed further.

Since the onset of foaming occurred slightly below the boiling point of water, we tried to eliminate it by progressively reducing the amounts of water and acetone (boiling point of $70 \mathrm{C}$ ) in the polymer/acetone mixture before the first curing stage. By reducing the pressure during the dessication step, more of the acetone and water could be evaporated before the first curing step. 
(a)

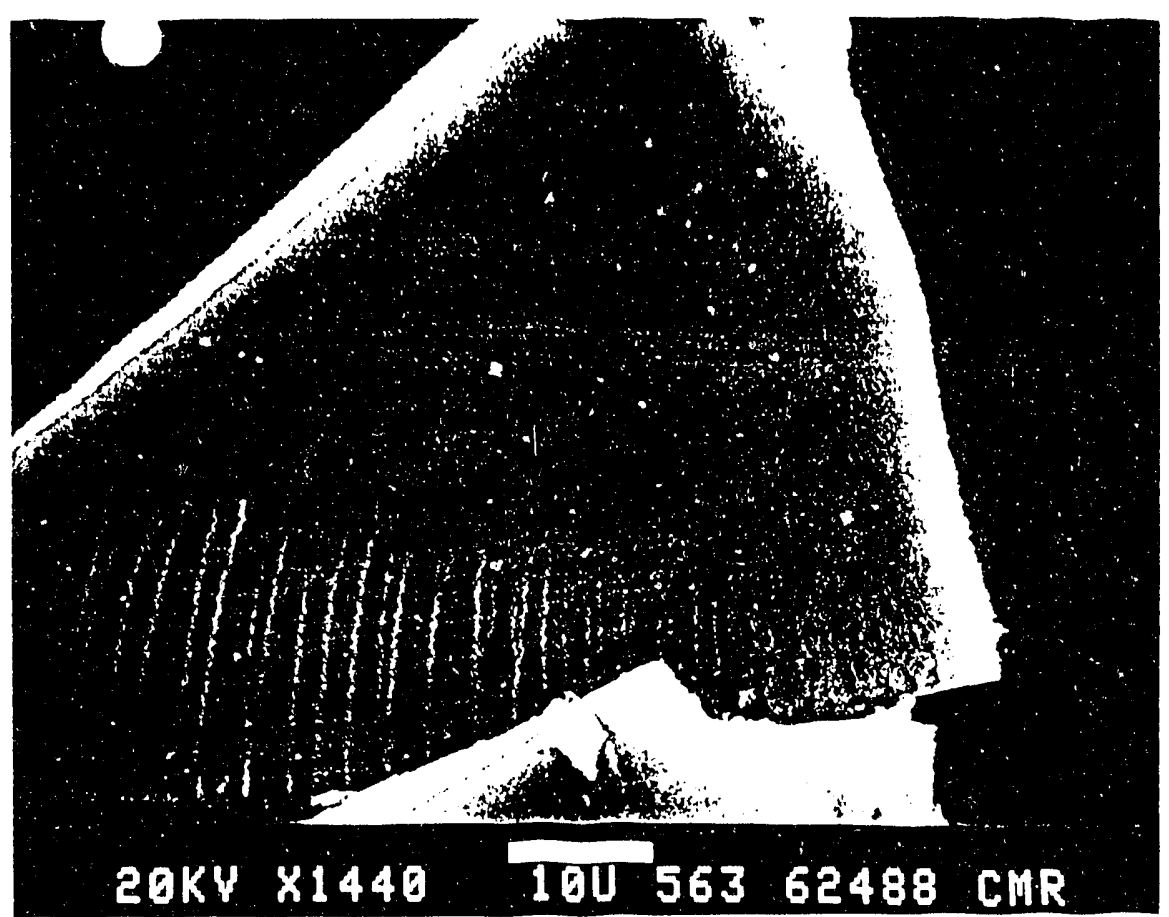

(b)

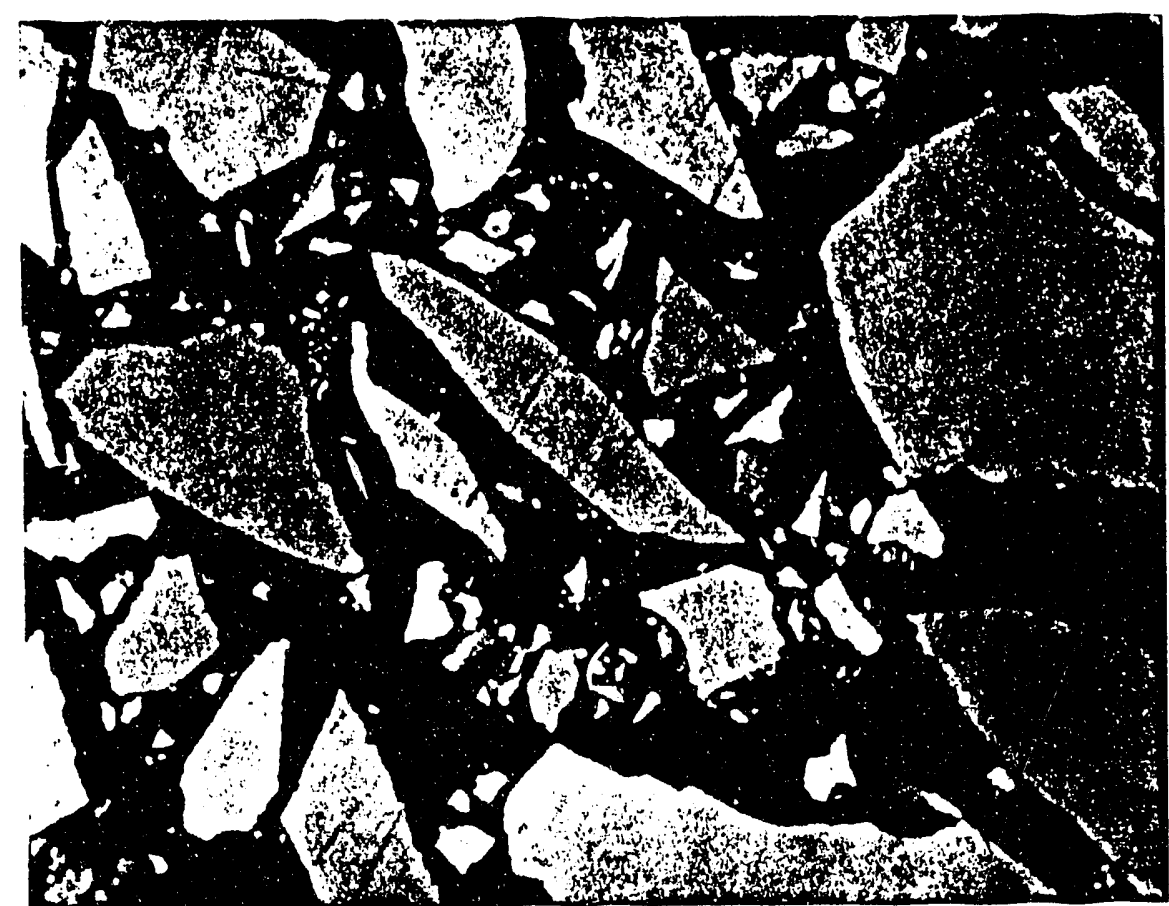

Figure 1. (a) SEM micrograph at $1440 \mathrm{X}$ of an individual, 100 micron carbon particle synthesized from furfuryl alcohol.

(b) SEM micrograph at $1250 \mathrm{X}$ of synthetic carbon ground into the pulverized fuel size grade, without any size classification. 
The weight loss from a series of samples at different dessication pressures appear in Table 2, along with the cumulative weight loss from the three distinct curing stages. These samples represent a wide range of acetone and water contents. Note that samples $\mathrm{C} 1, \mathrm{C} 2$, D1, D2, and F did not contain acetone. Furthermore, sample F contains no water, since the PTSA was added in crystalline form. Samples A, B1, C1, and D1 were dessicated under subatmospheric pressure, and lost more mass, as expected.

Despite these variations in volatiles content, the foaming was not completely eliminated in any sample. In fact, the foaming was about the same for all samples, with one exception. Only in sample $\mathrm{F}$, which contained no water, was the foaming almosr eliminated. We concluded that the dessication pressure and acetone content of the polymer can not be manipulated to eliminate foaming. Adiding the PTSA as crystals is also unsatisfactory, because it is only slightly soluble in alcohol, and will likely remain as inclusions in the carbon samples.

\section{Table 2}

Weight Loss of Polymer/Acetone Mixture at Various Stages of Char Synthesis*

\begin{tabular}{|lcccc|}
\hline Sample & Dessication** $^{* *}$ & $125 \mathrm{C}$ & $200 \mathrm{C}^{*}$ & $550 \mathrm{C}^{*}$ \\
\hline $\mathrm{A}$ & 9.6 & 19.5 & -- & -- \\
$\mathrm{B} 1$ & 8.4 & -- & 28.4 & -- \\
$\mathrm{B} 2$ & 6.6 & -- & 30.5 & -- \\
$\mathrm{C1}$ & 2.2 & -- & 15.2 & -- \\
$\mathrm{C}^{\dagger}$ & 1.1 & -- & 15.2 & -- \\
$\mathrm{Di}^{\dagger}$ & 2.3 & 10.4 & -- & - \\
$\mathrm{D2}^{\dagger}$ & 0.6 & 9.6 & -- & - \\
$\mathrm{E}$ & 11.7 & -- & -- & 43.3 \\
$\mathrm{~F}^{\dagger}$ & -0.5 & -- & -- & 43.1 \\
$\mathrm{G}$ & 10.3 & -- & 15.8 & 36.2 \\
\hline
\end{tabular}

*Weight loss in weight percent of original polymer/acetone mixture.

**For samples A, B2, C2, D2, E, F, anc G, pressure in dessicator was between 25 and 30 in $\mathrm{Hg}$, and for the rest, it was less than $10 \mathrm{in} \mathrm{Hg}$.

\#Values are cumulative for the preceding curing stage(s) only, without weight loss during Cessicatios.

${ }^{\dagger}$ No acetone was mixed with polymer. 


\section{SHORT RANGE OBJECTIVES}

During the coming quarter, we will continue to develop the synthesis procedures and classification methods for the samples in both the pyrite thermochemistry and fragmentation studies. They include extending the carbon synthesis to introduce very large voids into the samples, at controlled number density; classifying pyrite particles into tight size distributions centered about a few microns; introducing the pyrite inclusions into the synthetic chars; and density classifications to achieve uniform density, based on sedimentation in various liquids. As time permits, we will also characterize the mineral forms and elemental composition of these materials after curing, and after pretreatment at elevated temperatures.

\section{REFERENCES}

1. Senior, C., "Submicron Aerosol Formed During Combustion of Pulverized Coal," Ph.D. Thesis, California Institute of Technology, 1984. 
APPENDIX A:

DESIGN DRAWINGS FOR THE RAPID-QUENCHING SAMPLING PROBE 


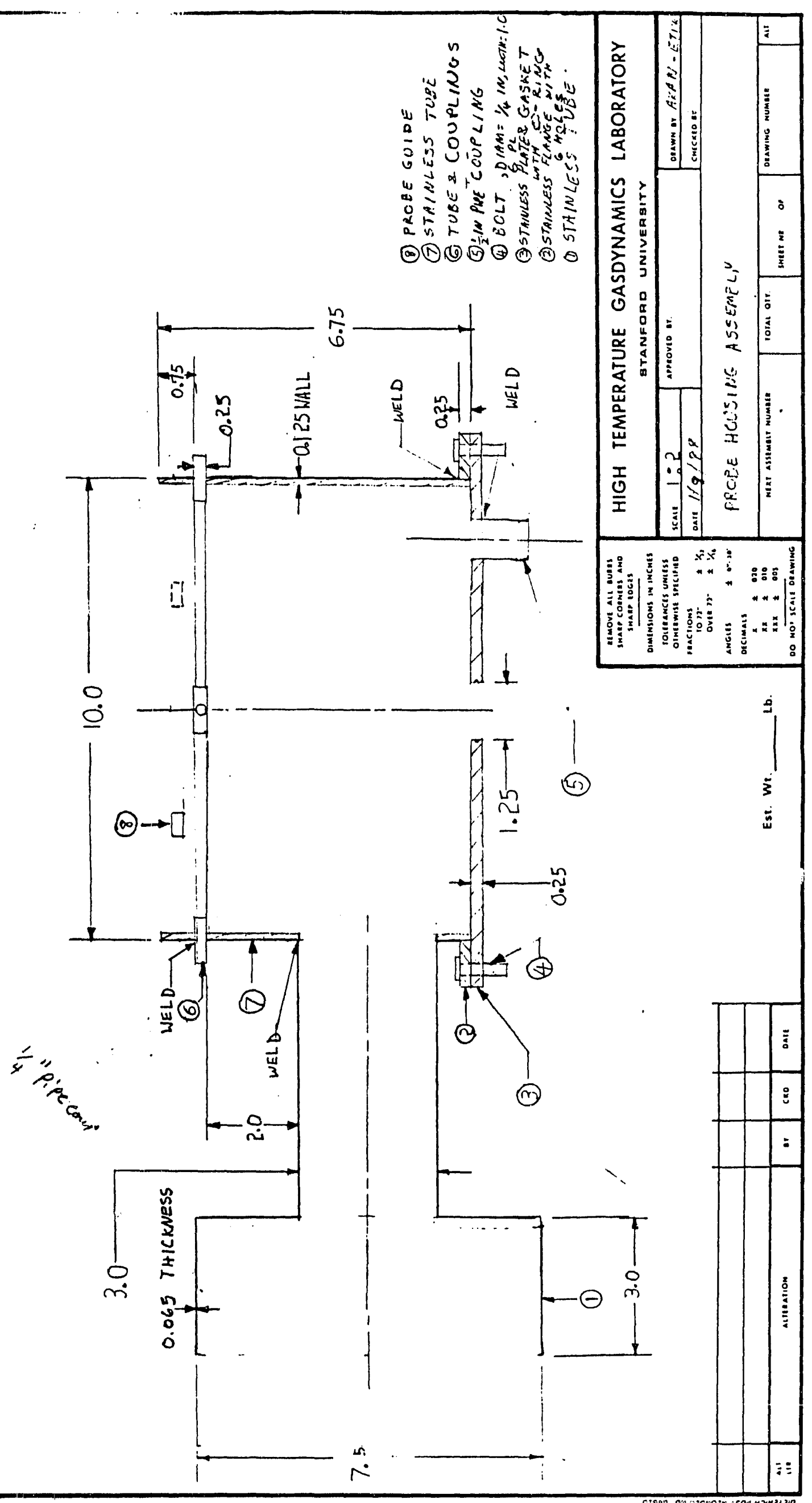




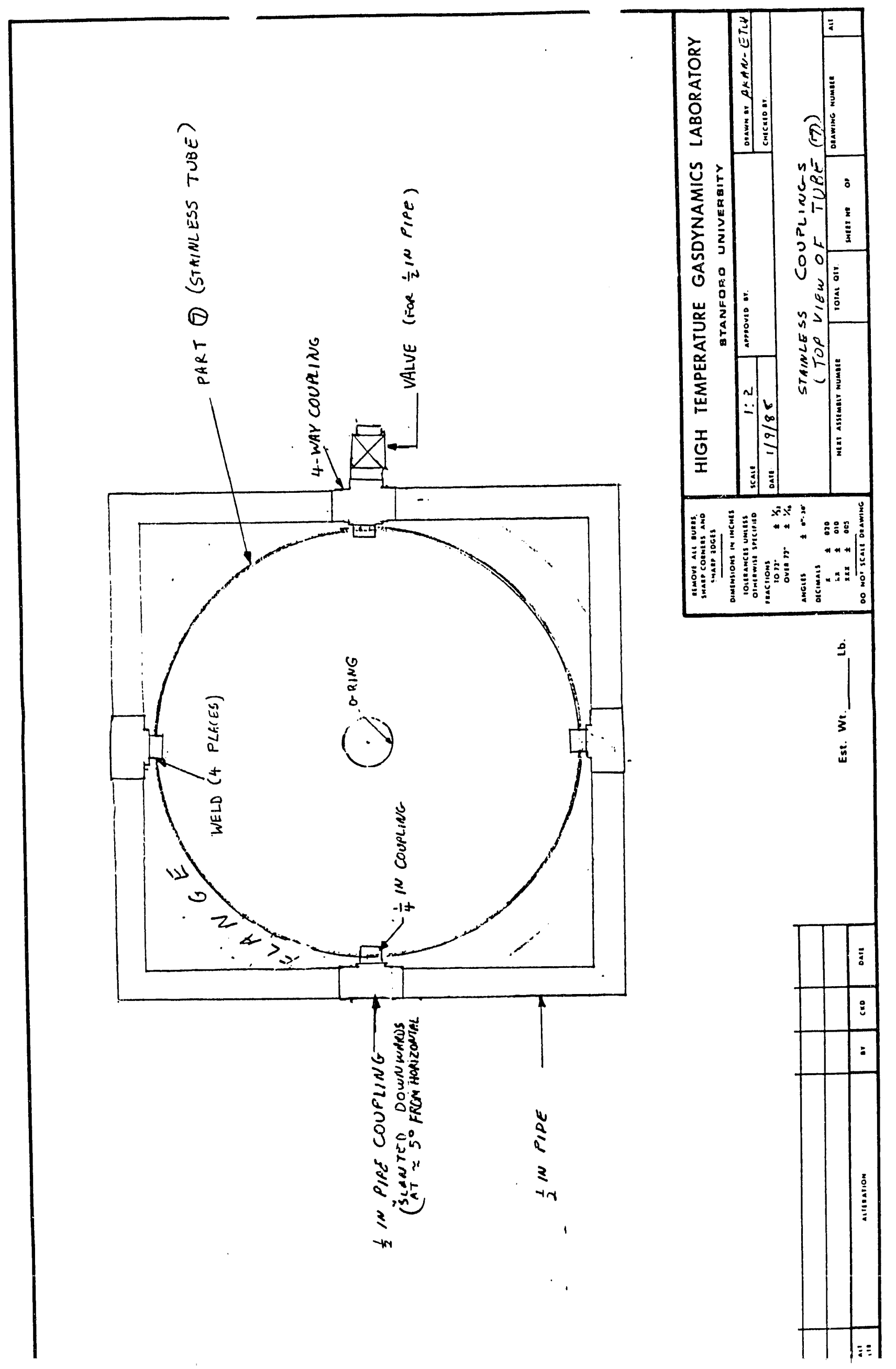




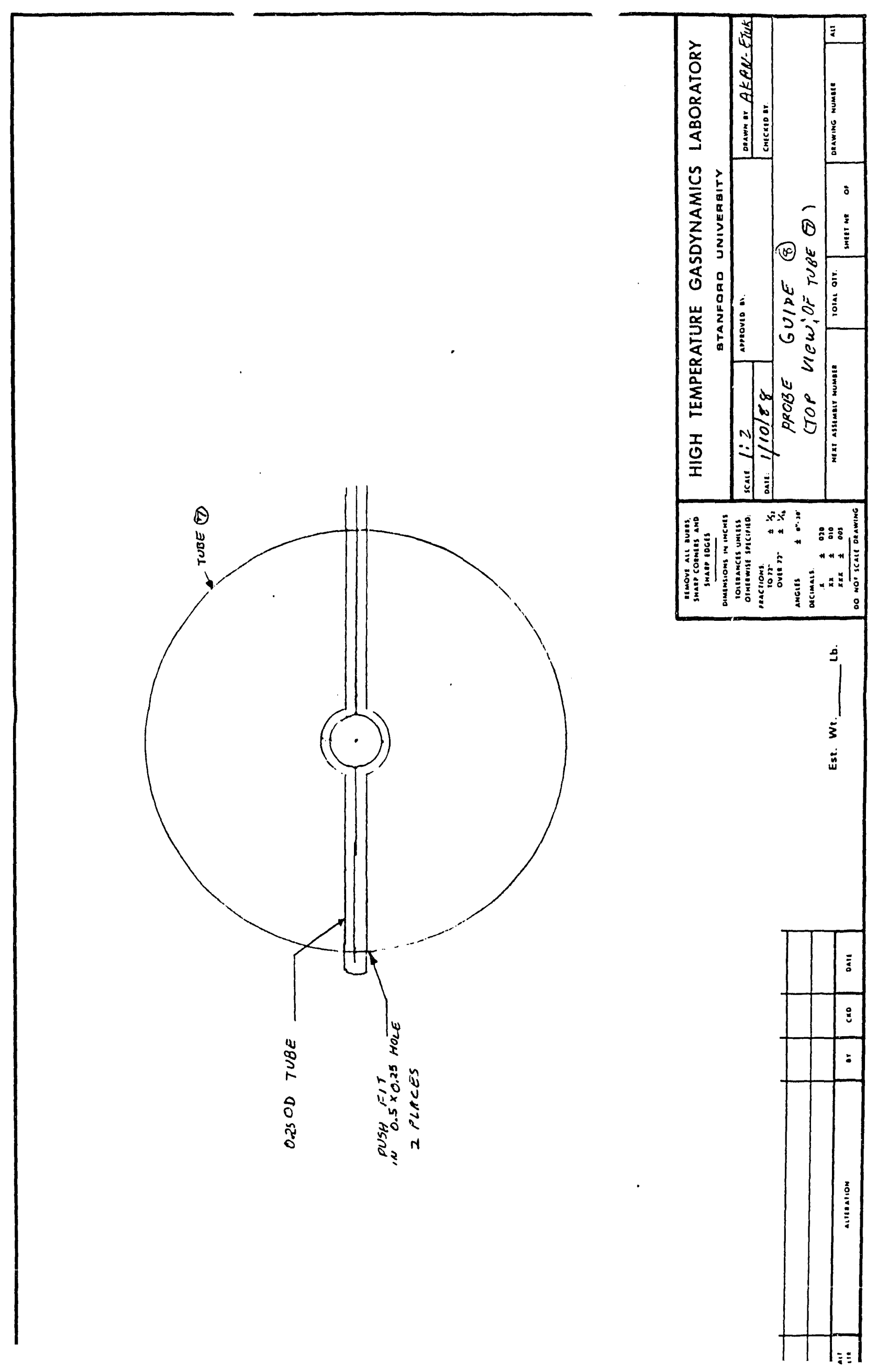




\section{APPENDIX B:}

\section{DETAILED PROCEDURES FOR SYNTHETIC CHAR POLYMERIZATION}

Synthetic chars in the form of billets of glassy carbon can be produced through the furfuryl alcohol polymerization process perfected by Senior (1). Although pyrite mineral inclusions or pore formers have not yet been added, Senior's char polymerization process was successfully repeated, with minor changes. Following are the steps for synthesis:

Step 1: The amount of polymer produced is dictated by how much can be cured at one time. Combine $30-40 \mathrm{ml}$ of furfuryl alcohol monomer with the catalyst, p-toluenesulfonic acid (PTSA), in a 200 or $250 \mathrm{ml}$ boiling flask. The catalyst is added in a water solution, $0.0451 \mathrm{~g} / \mathrm{ml}$, and is always $0.5 \%$ by weight of monomer.

Step 2: $\quad$ Fit the flask with a water cooled condenser and set in a water bath at 70-73 C for 10 minutes with constant stirring. Note that the amber colored liquid will turn dark brown as water is evolved violently. Finally a distinct aqueous phase will appear.

Step 3: Pour the contents of the flask into a $125 \mathrm{ml}$ separatory funnel and leave for one to one and a half hours.

Step 4: Weigh a $150 \mathrm{ml}$ beaker. Drain the viscous, dark brown polymer from the separatory funnel into the beaker, and discard the aqueous phase. Cover the beaker and weigh again. The amount of polymer is therefore determined.

\section{B: Addition of Solids}

At this point, two paths can be followed depending on whether or not carbon black is to be added.

I. Omitting carbon black - start with $40 \mathrm{ml}$ of furfuryl alcohol and $5.0333 \mathrm{ml}$ of PTSA solution (to obtain 30 to $36 \mathrm{~g}$ of polymer).

Step 5: Add $12 \mathrm{ml}$ of acetone to the contents of the $150 \mathrm{ml}$ beaker, cover and place in a ultrasonic bath. 
Step 6: Weigh the mineral matter and add to the beaker while in the bath.

Step 7: Mix the solution for 15 minutes using an overhead stirrer at 2000 rpm (the desired result can be obtained with a stirring rate as low as $1000 \mathrm{rpm}$ ). Note the formation of acetone bubbles.

Step 8: $\quad$ Pour the resulting mixture into four ceramic boats. Aspirate the boats using a vacuum dessicator for $4-1 / 2$ hours. Note that the quality of the ultimate product is insensitive to the dessication pressure.

II. Adding carbon black - start with $30 \mathrm{ml}$ of furfuryl alcohol monomer and $3.775 \mathrm{ml}$ of PTSA solution (to obtain 20 to $26 \mathrm{~g}$ of polymer).

Step 5: Add $70 \mathrm{ml}$ acetone to the contents of the $150 \mathrm{ml}$ beaker, cover and place in an 'sltrasonic bath.

Step 6: Veigh and add the mineral matter and carbon black separately. The ratio of zarbon black to polymer used is always 1:3.

Step 7: Mix the contents of the beaker using the overhead stirrer for 20 minutes at $2000 \mathrm{rpm}$ (or as low as $1000 \mathrm{rpm}$ ).

Step 8: $\quad$ Pour the resulting solution into the ceramic boats, and aspirate as described above for 4 hours.

\section{C: Curing}

Step 9: $\quad$ Place boats in furnace, and purge with nitrogen for 25 minutes.

Step 10: Heat the furnace to $125 \mathrm{C}$ at approximately $4 \mathrm{C} /$ minute. At $100 \mathrm{C}$, the polymer will start frothing as water boils off violently. By $125 \mathrm{C}$, the boiling has stopped, and the polymer has solidified, retaining the bubbles. Hold at $125 \mathrm{C}$ for 6 hours.

Step 11: Heat the furnace to $200 \mathrm{C}$ at approximately $3 \mathrm{C} /$ minute. Hold at $200 \mathrm{C}$ for 10 hours. 
Step 12: Increase the temperature of the furnace at a rate of $4-5 \mathrm{C} /$ minute till the soak temperature is reached. The soak temperature for carbon black is $550 \mathrm{C}$. Hold at this temperature for 1 hour. At this curing step, the oxygen level should be below a few hundred parts per million to avoid oxidation.

Step 13: Cool the boats in flowing nitrogen. The char produced is in the form of puffy' glassy carbon with centimeter-size bubbles.

D: Grinding

Step 14: Grind the char down to the desired size and sieve for thirty minutes using a mechanical shaker. For samples containing carbon black, the -400 mesh material should be removed and the material sieved again for thirty minutes.

\section{E: Storage}

Step 15: Dry the samples for 12 hours minimum at 105 C. Store the sample in a dessicator. 

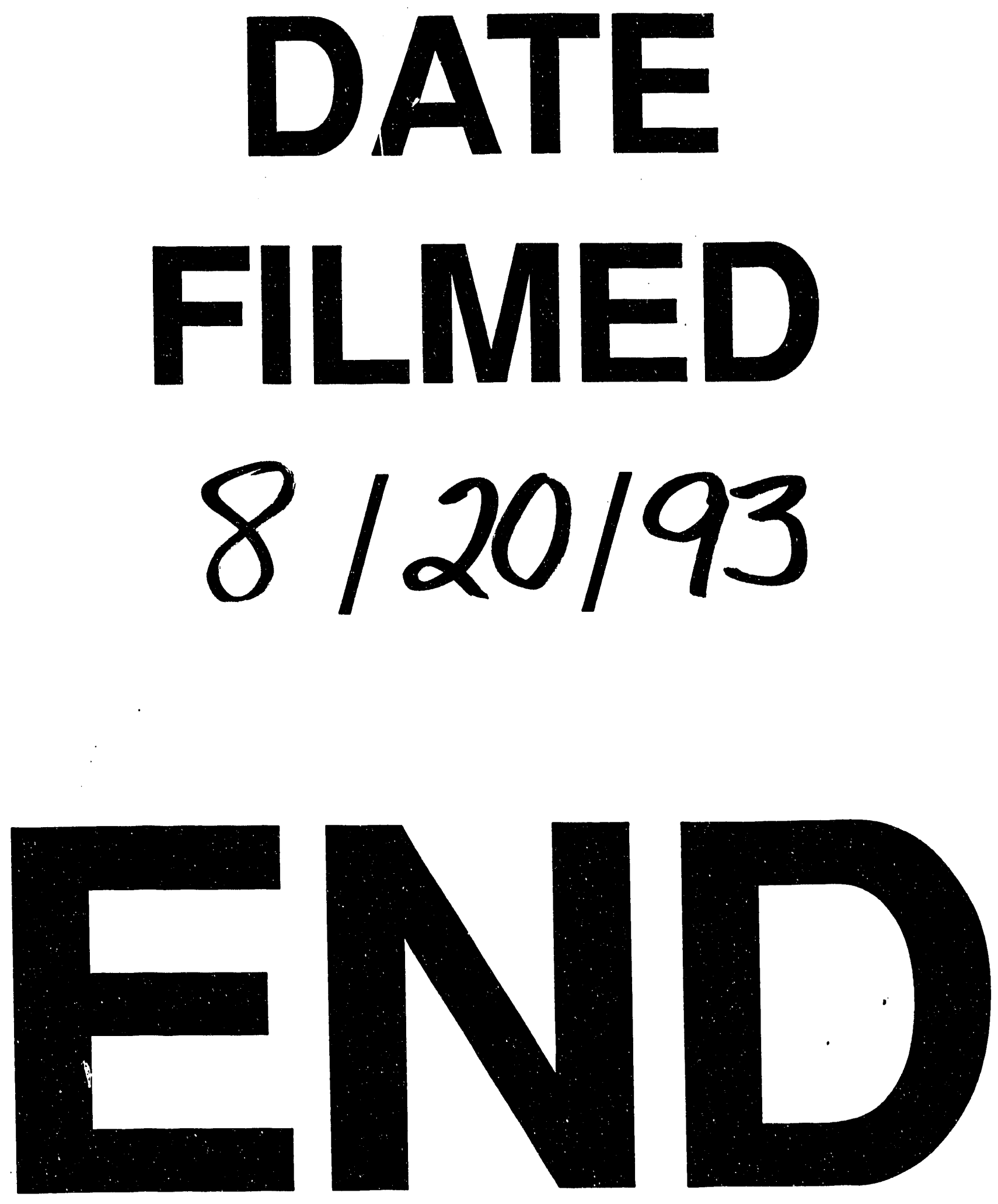
